\title{
Field Verification of Smoothness Requirements for Weigh-In-Motion Approaches
}

\author{
by \\ Dar-Hao Chen, Ph.D., P.E. \\ and \\ Feng Hong, Ph.D. \\ Report DHT-48 \\ Construction Division \\ Texas Department of Transportation \\ May 2008
}

\begin{abstract}
The smoothness of the pavement surface approaching a Weigh-In-Motion (WIM) scale directly affects the device's ability to accurately estimate static loads from measured dynamic forces. Lack of smoothness creates difficulties in obtaining an acceptable weighing error. Efforts were made in this study to determine appropriate threshold values of profile length and roughness approaching the WIM. Roughness data for 19 WIM sites across Texas were collected, and the corresponding calibration records from those WIM sites were employed to verify the smoothness threshold values proposed by AASHTO MP14 and ASTM E1318. Since there are multiple lanes at each WIM site, a total number of 70 profiles was surveyed. Based on the calibration records from the WIM sites and field roughness measurements, it was found that the upper threshold value of the Long Range Index (LRI) of AASHTO method MP14 needs to be adjusted in order to screen out the locations that yield unacceptable weighing error. The lower threshold value was found to be unnecessary because more than 90\% of WIM sites yielded acceptable weighing error even when exceeding the lower threshold value. The LRI is preferable to the Short Range Index (SRI) as it matched well with the field WIM calibration results. Based on the 70 profiles used to determine appropriate lengths, $25.8 \mathrm{~m}$ (85 ft) preceding the WIM, is found to be sufficient, which is the length required according to the LRI of AASHTO MP14. The ASTM

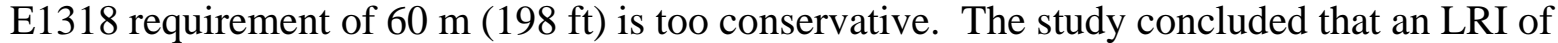
$1.74 \mathrm{~m} / \mathrm{km}(110 \mathrm{in} / \mathrm{mi})$ for the $25.8 \mathrm{~m}(85 \mathrm{ft})$ leading up to the WIM is the only critical factor in AASHTO MP14 and is the threshold value recommended.
\end{abstract}

Keywords: Weigh-in-Motion (WIM), Smoothness, Approach, Bending plate, Piezoelectric 


\section{Acknowledgements}

The support and assistance from Mike Moravec of FHWA, Magdy Mikhail, John Bilyeu, Cy Helms and Jim Neidigh of the Texas Department of Transportation are much appreciated. 


\section{Table of Contents}

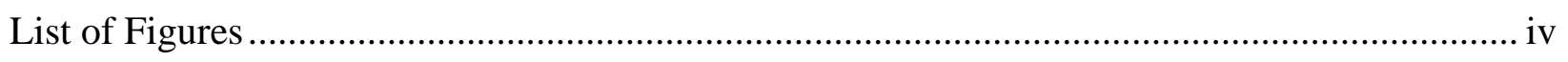

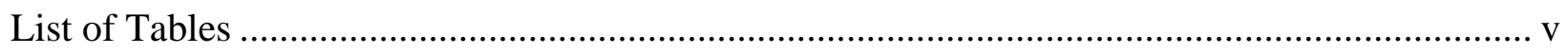

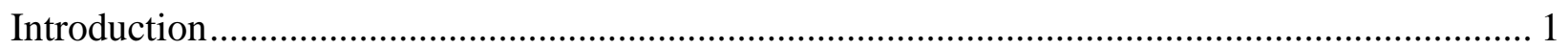

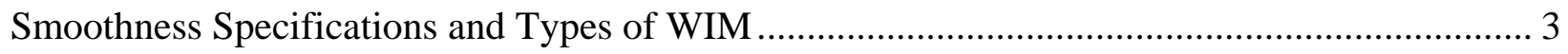

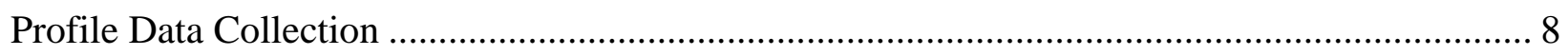

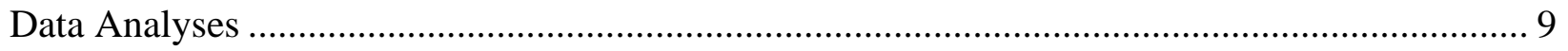

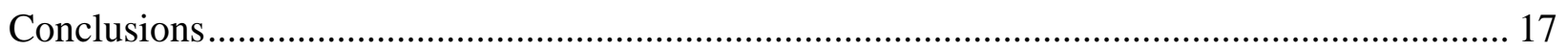

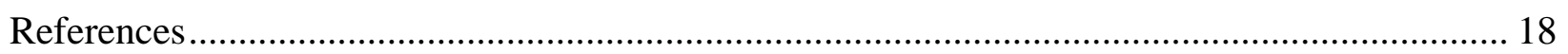




\section{List of Figures}

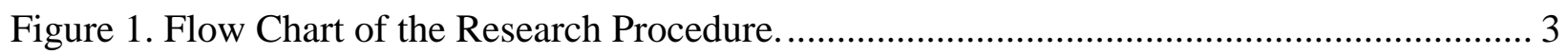

Figure 2. Geographical Distribution of Data Collection Sites at WIM Stations in Texas............... 6

Figure 3. Layout of Typical Bending Plate and Piezoelectric WIM Scales Used in Texas. .......... 6

Figure 4. TxDOT Profiler Used in WIM Approach Data Collection. .............................................. 8

Figure 5. An Example of Pavement Elevations at Both Wheel Tracks From 305 m (1000 ft)

Preceding to $305 \mathrm{~m}$ (1000 ft) Beyond a WIM Scale.................................................................... 9

Figure 6. Schematic of Pavement Approach Profile Collection at a WIM Site for Roughness

Index Calculation................................................................................................................ 9

Figure 7. A Snapshot Example of WIM Approach Smoothness Index Calculation Software by

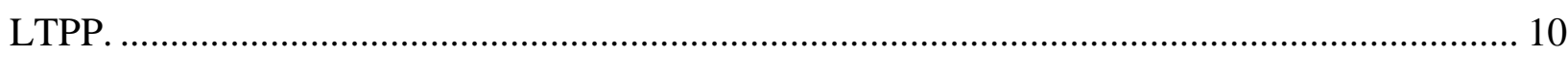

Figure 8. An Example of WIM Site with Smooth Approach (WIM 532 at Lane K6, SH 130)... 11

Figure 9. An Example of WIM Site with Rough Approach (WIM 4152 at Lane K1, SH 146)... 12

Figure 10. Distribution of Short Range Indices (SRI) for All 70 Pavement Approaches, From $3 \mathrm{~m}$

(10 ft) Preceding the Scale to $0.3 \mathrm{~m}$ (1 ft) Beyond It. 13

Figure 11. Distribution of Long Range Indices (LRI) for All 70 Pavement Approaches, From

$25.8 \mathrm{~m}$ (85 ft) Preceding the Scale to $3.2 \mathrm{~m}$ (11 ft) Beyond It..

Figure 12. Distribution of Long Range Indices (Additional LRI) at Pavement Approaches, 25.8

m (85ft) to $51.6 \mathrm{~m}$ (170 ft), Preceding the Scale Across All WIM Sites. 16 


\section{List of Tables}

Table 1. Roughness Index Thresholds for Type I WIM. ........................................................ 1

Table 2. Weigh-In-Motion Stations Information at Data Collection Sites Across Texas. ............ 7

Table 3. Summary Statistics of SRI and LRI Across All WIM Approaches.............................. 16 



\section{Introduction}

Traffic load data is one of the key components for reliable transportation infrastructure planning and pavement design/performance analysis $(1,2)$. Advanced Weigh-in-Motion (WIM) technology has become more popular in traffic load data collection among state highway agencies, due to its ability to continuously collect axle load data. The American Association of State Highway Transportation Officials (AASHTO) Standard Specification for Smoothness of Pavement at the Approaches to Weigh-In-Motion (WIM) Scales (AASHTO MP14) indicates that the smoothness of the pavement surface at the approach to a WIM scale directly affects the scale's ability to accurately estimate static loads from measured dynamic forces (3). Lack of smoothness creates difficulties in calibrating WIM equipment and may cause poor results from subsequent vehicle weight data collection efforts. The trucks' vertical motions affect the accuracy of the load data recorded at WIM scales (4). The usual practice is to provide a smooth pavement section to the WIM scale in order to minimize those motions. Karamihas and Gillespie documented that a smooth pavement section is needed for at least one truck length past the WIM scale (5). Maintaining a smooth pavement preceding and following the WIM scale (at least one truck length) can minimize the short-wavelength dynamic motions that are induced in the truck due to roughness. However, dynamic motions may still be induced if the pavement section exhibits long-wavelength undulations that tend to bounce the entire body of the vehicle (6).

Although AASHTO MP14 proposed lower and upper threshold values of long range and short range indices, it is strongly believed that improvements need to be made. As indicated by MP14 (see Table 1), the lower threshold values, $0.5 \mathrm{~m} / \mathrm{km}$ (32 in $/ \mathrm{mi}$ ), are those below which a WIM is very likely to produce an acceptable weighing error. Upper threshold values, $2.1 \mathrm{~m} / \mathrm{km}$ (133 $\mathrm{in} / \mathrm{mi}$ ), are those above which a WIM is very likely to produce an unacceptable weighing error. The lower and upper threshold values were developed by Karamihas and Gillespie through a series of computer simulations (6). The lower threshold value of $0.5 \mathrm{~m} / \mathrm{km}$ (32 in/mi) indicated a very smooth pavement which is believed impractical to construct and maintain. In addition, there are no explanations in MP14 about the outcome when the roughness falls between the lower and upper threshold values (a wide range of roughness). Based on roughness measurements from the Texas WIM sites, it was found that the majority (more than 90\%) of the WIM approach lanes in Texas fall between the lower and upper threshold values (see subsequent data analysis results). In these situations AASHTO MP14 does not indicate if the roughness values are acceptable or not.

Table 1. Roughness Index Thresholds for Type I WIM.

\begin{tabular}{|c|c|c|}
\hline Index & $\begin{array}{c}\text { Lower Threshold } \\
(\mathrm{m} / \mathrm{km}) /(\mathrm{in} / \mathrm{mi})\end{array}$ & $\begin{array}{c}\text { Upper Threshold } \\
(\mathrm{m} / \mathrm{km}) /(\mathrm{in} / \mathrm{mi})\end{array}$ \\
\hline LRI & $0.50 / 31.7$ & $2.10 / 133.1$ \\
\hline SRI & $0.50 / 31.7$ & $2.10 / 133.1$ \\
\hline Peak SRI & $0.75 / 47.5$ & $2.90 / 183.7$ \\
\hline
\end{tabular}

Through a national pooled fund study, validation tests were conducted on a Specific Pavement Study 1 (SPS1) site on US 281 in Texas on April 28, 2005. This site meets all Long-Term 
Pavement Performance (LTPP) loading precision requirements except speed, which is not considered sufficient to disqualify the site from having research-quality data. This site meets the overall classification requirement of having less than $2 \%$ unclassified axle groups. The validation used the following trucks: 1) 3S2 with a tractor having an air suspension tandem and a trailer with a standard tandem and air suspension, loaded to 345,111 N (77,650 lbs), 2) 3S3 with a tractor having a walking beam suspension tandem and trailer, with a tridem air ride suspension, loaded to 355,289 N (79,940 lbs), and 3) 3S2 with a tractor having an air suspension tandem and a trailer with a standard rear tandem and a leaf spring suspension, loaded to 253,289 N (56,990 lbs). Profile data was collected in April 2005 and used to evaluate the criteria proposed by AASHTO MP14. The International Roughness Index (IRI) values were about $60-80 \mathrm{in} / \mathrm{mi}$ (0.9$1.3 \mathrm{~m} / \mathrm{km}$ ) for the $152.4 \mathrm{~m}$ (500 ft) concrete section, with the WIM installed at $121.9 \mathrm{~m}(400 \mathrm{ft})$. Although the US 281 site would not pass the short-range and long-range roughness indices of $0.50 \mathrm{~m} / \mathrm{km}$ (32 in/mi), based on the verification tests with different trucks, the site did meet the accuracy requirements. This means the $0.50 \mathrm{~m} / \mathrm{km}$ (32 in $/ \mathrm{mi}$ ) requirement may be too conservative. So far, no State Highway Agency has reported on any testing to evaluate the roughness of WIM approaches using the lower and upper threshold values. However, there is some literature providing field validation results on the acceptable roughness indices.

American Society of Testing Materials (ASTM) E1318 requires checking the longitudinal gradient of the road profile for $60 \mathrm{~m}$ (200 ft) in advance of, and $30 \mathrm{~m}(100 \mathrm{ft})$ beyond the WIM system (7). However, the long-range roughness index proposed by AASHTO MP14 requires

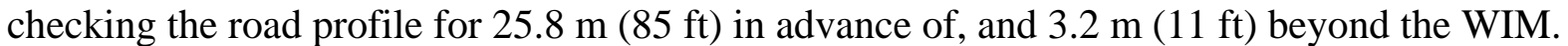
There are significant discrepancies between ASTM E1318 and AASHTO MP14. The requirements of the two methods differ by a factor of more than two. This stresses the importance of improving the current threshold roughness values as well as the length requirement.

The main purpose of this study was to advance the development of roughness specifications for WIM scale approaches. The research steps are summarized in the flow chart (see Figure 1) and detailed as follows. Roughness measurements were conducted on 19 WIM sites across Texas (see Figure 2), and included approaches from different lanes and different directions. A total of 70 roughness measurements were used in this study. Calibration records from the 19 WIM sites were employed to determine if the WIMs yield an acceptable weighing error per ASTM E1318 requirements. Calibration records indicated that several sites yielded an unacceptable weighing error. Thus, the field roughness measurements along with the calibration records provide an opportunity to verify and improve the existing threshold values outlined by AASHTO MP14 and ASTM E1318. Statistical analysis was utilized to determine the threshold roughness value that would yield an acceptable weighing error. 


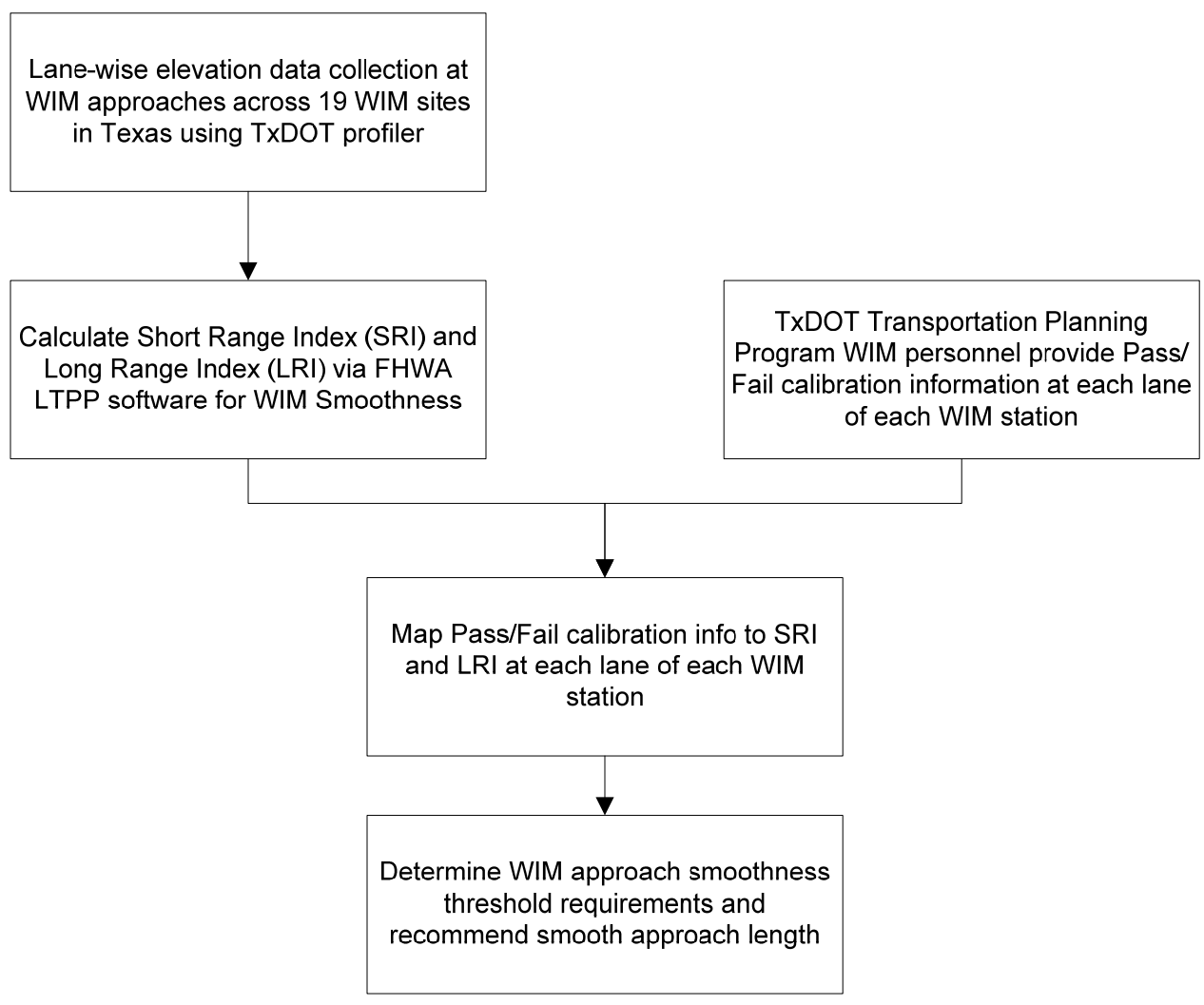

Figure 1. Flow Chart of the Research Procedure.

\section{Smoothness Specifications and Types of WIM}

Both ASSHTO MP14 and ASTM E1318 provide guidelines and threshold values for WIM approaches. The smoothness threshold values and required approach lengths are different between those two specifications. Summaries of requirements for both methods are given in subsequent sections. In addition, different types of WIM scales were utilized in this study. Brief descriptions of the WIMs are presented.

\section{Smoothness Specifications -AASHTO MP14}

The smoothness specifications were originally developed to facilitate data collection through WIM scales at LTPP's Specific Pavement Studies (SPS) sites (8). Karamihas and Gillespie have developed short and long range profile-based indices that can facilitate predicting the potential WIM error level due to roughness of the approach (5). Both a short range near the scale, and a longer range leading up to the scale were examined. These were given the names of Short Range Index (SRI) and Long Range Index (LRI), respectively. "Short Range" roughness covers the range of pavement from about $3 \mathrm{~m}(10 \mathrm{ft})$ preceding the scale, the scale itself, to about $0.3 \mathrm{~m}$ ( $1 \mathrm{ft}$ ) beyond it. In contrast, "Long Range” roughness includes about $25 \mathrm{~m}(83 \mathrm{ft})$ preceding the scale, the scale itself, and about $3 \mathrm{~m} \mathrm{(10} \mathrm{ft)} \mathrm{beyond} \mathrm{it.} \mathrm{LRI} \mathrm{characterizes} \mathrm{the}$ "background" roughness for a relatively long distance leading up to the scale and a short distance beyond it. 
In Karamihas and Gillespie's study, WIM scale error was related to profile characteristics using a large simulation study of the response of 3,696 virtual five-axle tractor-semitrailers over 63 measured profiles of the LTPP sections (5). A distribution error was compiled over the truck population for steer axle, tandem axle, and total vehicle weight at each site. The error distributions were summarized by their $95^{\text {th }}$ percentile absolute error levels. The error levels assigned to each site were used as a correlation standard for proposed roughness indices. The ASTM error tolerances (Type I) for weigh-scale performance call for $95 \%$ confidence that: (1) steer axle load will be measured within $20 \%$, (2) tandem axle load will be measured within $15 \%$, and (3) gross vehicle load will be measured within $10 \%$ (7). Functional performance requirements for Types I and II WIM systems were established and tabulated in ASTM E1318. Although the LRI and SRI indices were established based on the five-axle tractor-semitrailers, those indices have been verified by three-axle straight trucks (6).

The threshold values for LRI and SRI given by AASHTO MP14 are presented in Table 1. "Peak

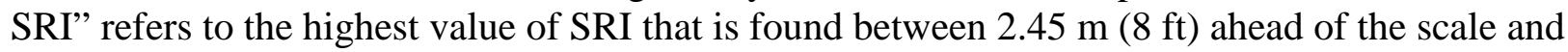

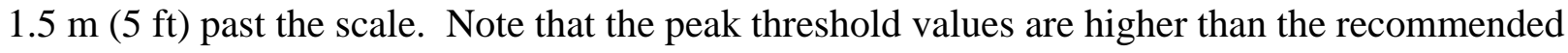
values for SRI. This is because the index at the scale location is most critical, and the peak SRI is used to screen for excessive localized roughness. AASHTO MP14 also recommends that the peak LRI limit should be $30 \mathrm{~m}(100 \mathrm{ft})$ leading up to the scale, to protect against extremely rough pavement that is out of the range of the LRI at the scale. Note that the $30 \mathrm{~m}(100 \mathrm{ft})$ range is considered a minimum. The very presence of a WIM scale will often create localized roughness of the pavement in its vicinity. If this localized roughness is just outside the range of the SRI, $2.8 \mathrm{~m}(9 \mathrm{ft})$ preceding a WIM scale to $0.5 \mathrm{~m}(1.7 \mathrm{ft})$ beyond it, then it will elevate the WIM error levels without any effect on the SRI value. To account for this, a peak SRI value needs to be calculated. This value is defined as the maximum SRI for all locations from $2.45 \mathrm{~m}(8 \mathrm{ft})$ ahead

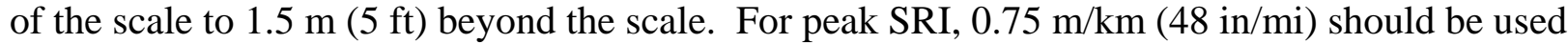
as the acceptable threshold for a Type I WIM, and $1.6 \mathrm{~m} / \mathrm{km}(101 \mathrm{in} / \mathrm{mi})$ should be used for a Type II WIM.

\section{Smoothness Specifications -ASTM E1318}

ASTM E1318 indicates that to ensure reliable WIM system performance, the surface of the paved roadway $60 \mathrm{~m}$ (200 ft) in advance of, and $30 \mathrm{~m}(100 \mathrm{ft})$ beyond the WIM system sensors shall be smooth prior to sensor installation, and maintained in a condition such that a $150 \mathrm{~mm}$ (6 in) diameter, $3 \mathrm{~mm}$ (0.125 in) thick circular plate cannot be passed beneath a $6 \mathrm{~m}(20 \mathrm{ft})$ long straightedge. Note that the Texas Department of Transportation (TxDOT) currently uses ASTM E1318 to prepare the WIM approaches.

ASTM E1318 suggests that, beginning at the longitudinal center of the WIM sensor array, a straightedge should be placed along each respective lane edge with the end furthest from the sensors at the distances from the longitudinal center of the sensors as given below. Then the straightedge should be pivoted about this end and the end nearest the sensors swept between the lane edges, while checking clearance beneath the straightedge with a circular plate. The

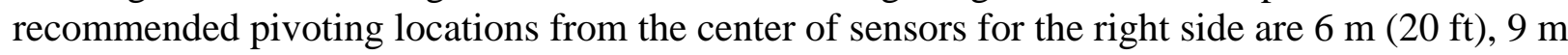
(30 ft), $13 \mathrm{~m}$ (43 ft), $18 \mathrm{~m}$ (60 ft), $23 \mathrm{~m}$ (76 ft), $28 \mathrm{~m}(92 \mathrm{ft}), 33 \mathrm{~m}(109 \mathrm{ft}), 38 \mathrm{~m}(125 \mathrm{ft}), 43 \mathrm{~m}$

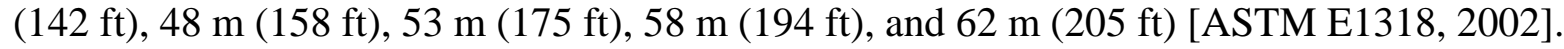
Similarly, the pivoting locations for the left side are $6 \mathrm{~m}(20 \mathrm{ft}), 11 \mathrm{~m}(36 \mathrm{ft}), 16 \mathrm{~m}(53 \mathrm{ft}), 21 \mathrm{~m}$ (69 ft), 26 m (86 ft), 30 m (99 ft), 35 m (116 ft), 40 m (132 ft), 45 m (149 ft), 50 m (165 ft), 55 m $(182 \mathrm{ft}), 60 \mathrm{~m}(198 \mathrm{ft})$, and $65 \mathrm{~m}(215 \mathrm{ft})$. 
In practice, the procedure outlined by ASTM is tedious, labor intensive, and cumbersome. Highspeed profilers that measure roughness are available to almost all state highway agencies. In conjunction with AASHTO MP14, the quality control and quality assurance of the smoothness of the WIM approaches can be easily implemented. As aforementioned, however, AASHTO MP14 is derived from computer simulations, and it needs field verification. To accomplish this, field WIM calibration records were utilized to determine the required approach length and other critical threshold values.

\section{Types of WIM}

Among a variety of alternatives, the current WIM scales used in the U.S. can be divided into three major categories based on different sensor technologies (9):

1. Piezoelectric sensor: The basic components of the typical sensor consist of a load bearing pad and sensing elements. When pressure is applied to the load bearing pad, an electrical charge is produced. Through a conversion between the charge produced and weight, the weight of a passing tire or axle group can be obtained.

2. Bending plate: A bending plate scale consists of two steel platforms, each $0.6 \mathrm{~m}(2 \mathrm{ft})$ by 1.8 $\mathrm{m}(6 \mathrm{ft})$, usually installed in a staggered fashion. The steel plate is instrumented with strain gages to measure the strain in the plate as a load passes over, which in turn is converted to weight through an established algorithm.

3. Load cell: A load cell scale consists of two weighing platforms with a surface of $1.8 \mathrm{~m}$ by $0.9 \mathrm{~m}$ (6 ft by $3 \mathrm{ft} 2 \mathrm{in}$ ), placed adjacent to each other to fully cover a normal 12-foot traffic lane. A single hydraulic load cell, consisting of a single oil-filled piston, is installed at the center of each platform to measure the force applied to the scale. The load measurements are recorded and analyzed by the system electronics to determine tire and axle loads.

In addition to these three types of sensors, TxDOT has installed WIM with quartz sensors. Like the piezoelectric sensor, the quartz sensor determines vehicle axle weight through and electrical charge generated by a quartz disc due to applied force on it. The WIM with the quartz sensor is well received with good results in field implementation.

The 19 sites investigated in this study consist of 1 quartz WIM, 7 piezoelectric WIMs, and 11 bending plate WIMs, as shown in Figure 2 and Table 2. Figure 3 illustrates examples of in-field layout of piezoelectric and bending plate WIM scales in Texas. Table 2 illustrates that bending plate type WIMs were installed in all continuous reinforced concrete pavements (CRCP). All CRCPs have scale installation pads $120 \mathrm{~m}(400 \mathrm{ft})$ in advance of and $30 \mathrm{~m}(100 \mathrm{ft})$ beyond the WIM bending scale. All asphalt pavements have piezoelectric sensor type WIMs. 


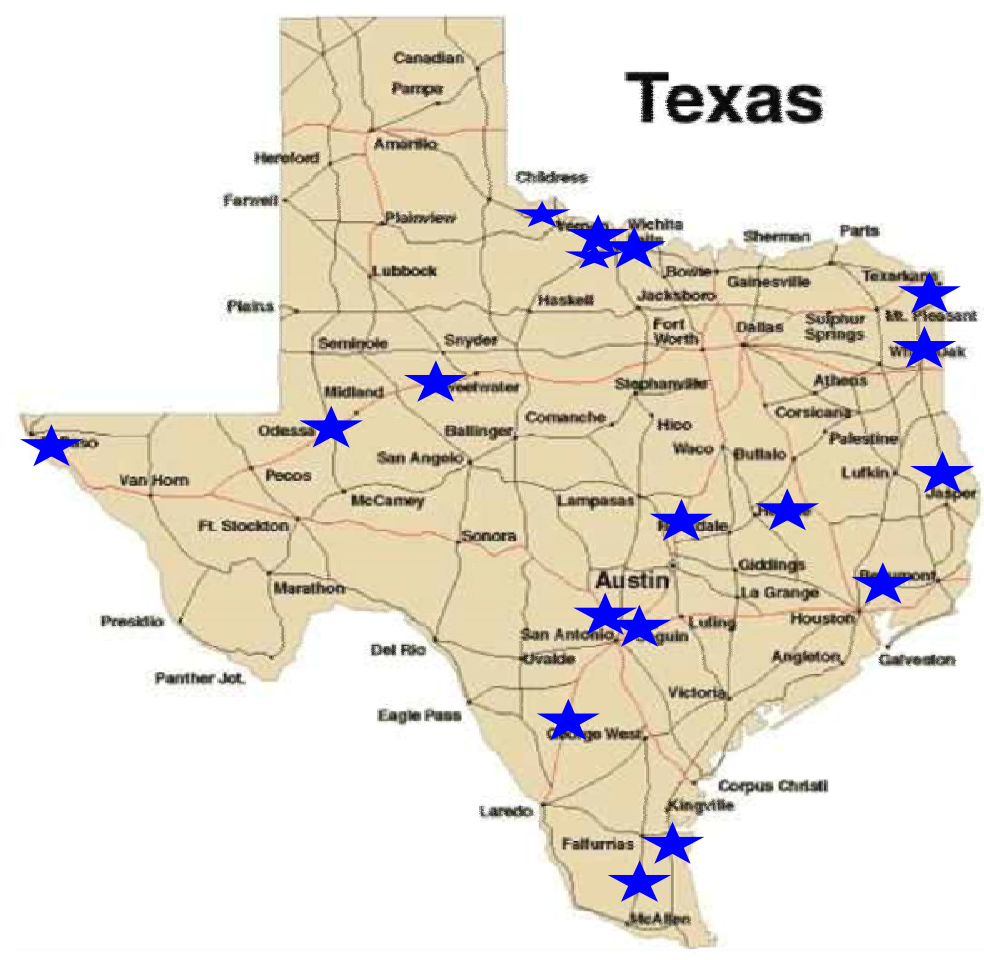

Figure 2. Geographical Distribution of Data Collection Sites at WIM Stations in Texas.

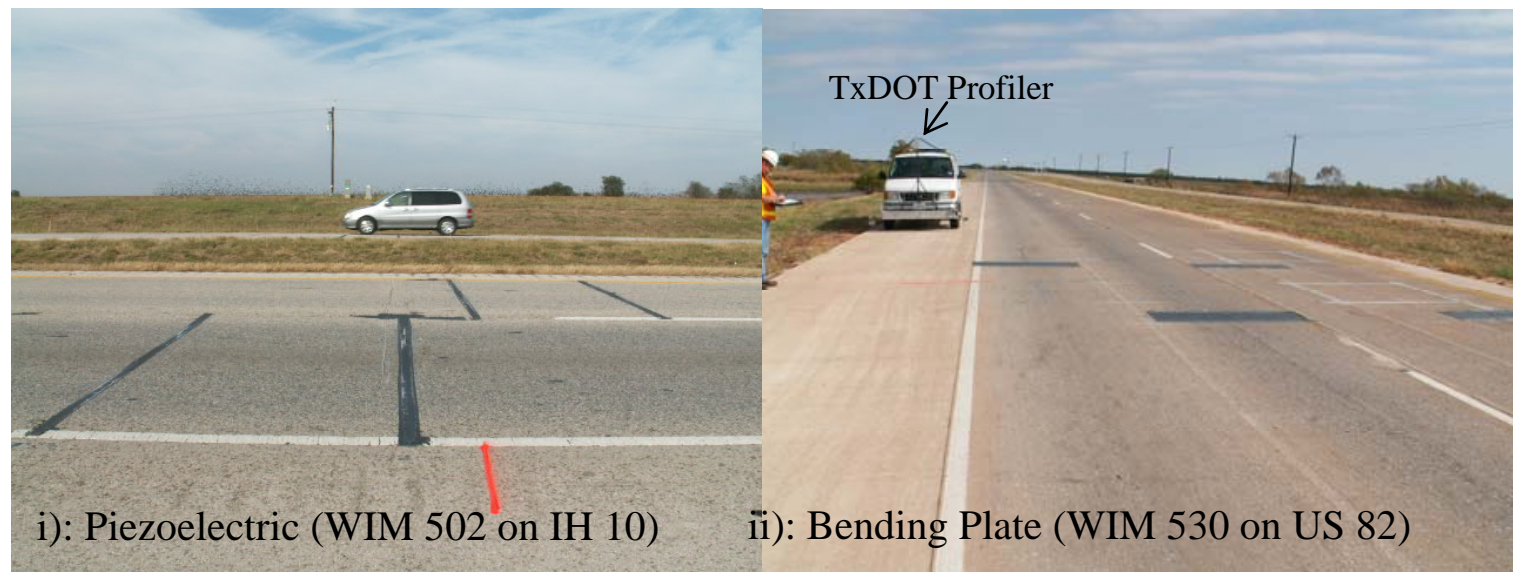

Figure 3. Layout of Typical Bending Plate and Piezoelectric WIM Scales Used in Texas. 
Table 2. Weigh-In-Motion Stations Information at Data Collection Sites Across Texas.

\begin{tabular}{|c|c|c|c|c|c|c|c|}
\hline $\begin{array}{l}\text { WIM } \\
\text { Site ID }\end{array}$ & Route & $\begin{array}{l}\text { Approach } \\
\text { Pavement } \\
\text { Type } \\
\end{array}$ & Sensor Type & $\begin{array}{c}\text { \# of } \\
\text { Lanes }\end{array}$ & $\begin{array}{c}\text { LRI* } \\
(\mathrm{m} / \mathrm{km}) /(\mathrm{in} / \mathrm{mi})\end{array}$ & $\begin{array}{c}\text { SRI* } \\
(\mathrm{m} / \mathrm{km}) \\
/(\mathrm{in} / \mathrm{mi}) \\
\end{array}$ & $\begin{array}{c}\text { Pass } \\
\text { Calibration? }\end{array}$ \\
\hline 502 & IH 10 & Asphalt & PIEZO & 4 & $\begin{array}{c}0.80 \sim 1.20 \\
/ 50.4 \sim 75.6 \\
\end{array}$ & $\begin{array}{l}0.54 \sim 1.11 \\
/ 34.0 \sim 69.9\end{array}$ & Yes \\
\hline 506 & US 287 & Concrete & B-PLATE & 4 & $\begin{array}{c}0.72 \sim 1.64 \\
/ 45.4 \sim 103.3\end{array}$ & $\begin{array}{c}0.99 \sim 3.08 \\
/ 62.4 \sim 194.0 \\
\end{array}$ & Yes \\
\hline 518 & IH10 & Asphalt & PIEZO & 4 & $\begin{array}{l}0.98 \sim 1.23 \\
/ 61.7 \sim 77.5\end{array}$ & $\begin{array}{c}1.25 \sim 1.85 \\
/ 78.8 \sim 116.6 \\
\end{array}$ & Yes \\
\hline 519 & IH 20 & Asphalt & PIEZO & 4 & $\begin{array}{c}0.76 \sim 1.15 \\
/ 47.9 \sim 72.5\end{array}$ & $\begin{array}{l}0.65 \sim 1.41 \\
/ 41.0 \sim 88.8\end{array}$ & Yes \\
\hline 523 & US 281 & Concrete & B-PLATE & 4 & $\begin{array}{c}0.73 \sim 1.51 \\
/ 46.0 \sim 95.1 \\
\end{array}$ & $\begin{array}{c}0.45 \sim 1.53 \\
/ 28.4 \sim 96.4 \\
\end{array}$ & Yes \\
\hline 524 & IH 10 & Concrete & B- PLATE & 4 & $\begin{array}{l}0.72 \sim 1.49 \\
/ 45.4 \sim 93.9\end{array}$ & $\begin{array}{c}0.69 \sim 1.62 \\
/ 43.5 \sim 102.1\end{array}$ & Yes \\
\hline 525 & US59 & Concrete & B-PLATE & 4 & $\begin{array}{c}1.00 \sim 1.17 \\
/ 63.0 \sim 73.7\end{array}$ & $\begin{array}{l}0.66 \sim 1.06 \\
/ 41.6 \sim 66.8\end{array}$ & Yes \\
\hline 526 & IH20 & Concrete & B-PLATE & 4 & $\begin{array}{l}1.00 \sim 1.22 \\
/ 63.0 \sim 76.9\end{array}$ & $\begin{array}{c}0.79 \sim 1.79 \\
/ 49.8 \sim 112.8\end{array}$ & Yes \\
\hline 527 & SH 114 & Concrete & B-PLATE & 4 & $\begin{array}{c}0.81 \sim 1.12 \\
/ 51.0 \sim 70.6\end{array}$ & $\begin{array}{l}0.65 \sim 1.28 \\
/ 41.0 \sim 80.6 \\
\end{array}$ & Yes \\
\hline 528 & US 287 & Concrete & B-PLATE & 4 & $\begin{array}{l}0.75 \sim 1.25 \\
/ 47.3 \sim 78.8 \\
\end{array}$ & $\begin{array}{c}0.53 \sim 0.91 \\
/ 33.4 \sim 57.3 \\
\end{array}$ & Yes \\
\hline 529 & US 287 & Concrete & B-PLATE & 4 & $\begin{array}{c}0.87 \sim 1.71 \\
/ 54.8 \sim 107.7\end{array}$ & $\begin{array}{c}1.18 \sim 3.48 \\
/ 74.3 \sim 219.2\end{array}$ & Yes \\
\hline 530 & US 277 & Concrete & B-PLATE & 4 & $\begin{array}{c}0.50 \sim 0.94 \\
/ 31.5 \sim 59.2 \\
\end{array}$ & $\begin{array}{c}1.07 \sim 1.68 \\
/ 67.4 \sim 105.8 \\
\end{array}$ & Yes \\
\hline 531 & IH 35 & $\begin{array}{l}\text { Northbound: } \\
\text { Concrete } \\
\text { Southbound: } \\
\text { Asphalt }\end{array}$ & Quartz & 4 & $\begin{array}{l}0.65 \sim 0.90 \\
/ 41.0 \sim 56.7\end{array}$ & $\begin{array}{c}0.40 \sim 0.84 \\
/ 25.2 \sim 52.9\end{array}$ & Yes \\
\hline 532 & SH 130 & Concrete & B-PLATE & 4 & $\begin{array}{c}0.57 \sim 0.67 \\
/ 35.9 \sim 42.2\end{array}$ & $\begin{array}{c}0.30 \sim 0.64 \\
/ 18.9 \sim 40.3\end{array}$ & Yes \\
\hline 533 & IH 20 & Concrete & B-PLATE & 4 & $\begin{array}{c}0.70 \sim 0.98 \\
/ 44.1 \sim 61.7 \\
\end{array}$ & $\begin{array}{c}0.69 \sim 1.21 \\
\text { /43.5 76.2 } \\
\end{array}$ & Yes \\
\hline 800 & $\begin{array}{c}\text { FM } \\
2223\end{array}$ & Asphalt & PIEZO & 2 & $\begin{array}{c}0.91 \sim 3.86 \\
/ 57.3 \sim 243.2\end{array}$ & $\begin{array}{l}0.82 \sim 0.93 \\
/ 51.7 \sim 58.6\end{array}$ & $\begin{array}{c}\text { Yes, } \\
\text { Southbound } \\
\text { only }\end{array}$ \\
\hline 074 & US 77 & Asphalt & PIEZO & 4 & $\begin{array}{c}0.60 \sim 1.74 \\
/ 37.8 \sim 109.6 \\
\end{array}$ & $\begin{array}{l}0.54 \sim 0.85 \\
/ 34.0 \sim 53.6 \\
\end{array}$ & Yes \\
\hline 4142 & US 96 & Asphalt & PIEZO & 4 & $\begin{array}{c}1.19 \sim 2.07 \\
/ 75.0 \sim 130.4\end{array}$ & $\begin{array}{c}0.77 \sim 2.08 \\
/ 48.5 \sim 131.0\end{array}$ & $\begin{array}{c}\text { Yes, } \\
\text { Northbound } \\
\text { only }\end{array}$ \\
\hline 4152 & RM452 & Asphalt & PIEZO & 4 & $\begin{array}{c}2.34 \sim 3.09 \\
/ 147.4 \sim 194.7\end{array}$ & $\begin{array}{c}2.42 \sim 2.90 \\
/ 152.5 \sim 182.7\end{array}$ & No \\
\hline
\end{tabular}

*Roughness indices range across all lanes of the underlying WIM site. 
According to TxDOT WIM management personnel at the Transportation Planning and Programming Division, piezoelectric type WIMs cost approximately 90\% less than bending plate type WIMs. However, based on the field observations and collected data, piezoelectric sensors are found to be temperature sensitive, hard to keep calibrated, and require more frequent calibrations.

TxDOT is in the process of constructing additional WIM sites to reach a total of 100 WIM sites statewide. This number is a target based on the Traffic Monitoring Guide recommendation in terms of states creating truck weight groups and collecting weight data by functional class within each region. This would provide more localized pavement data by region. Smoothness criteria for those WIM sites are critically needed. TxDOT currently has 21 WIM sites that are able to generate weight tables for pavement design and analysis purposes. In order to obtain reliable traffic data collection, these WIM scales are frequently calibrated by TxDOT personnel. During the calibration process, a typical five-axle test truck is employed. The gross vehicle weight (GVW) of the test truck is approximately $356 \mathrm{kN}$ (80 kips). Four repeated runs are carried out under a given speed based on the posted legal limit, e.g., $50 \mathrm{mph}(90 \mathrm{~km} / \mathrm{h}), 60 \mathrm{mph}(96 \mathrm{~km} / \mathrm{h})$, or $70 \mathrm{mph}(112 \mathrm{~km} / \mathrm{h})$, at the WIM sites. The WIM scale is regarded as "passing" when the difference between WIM estimated GVW and the static weighed GVW is within 3\%. The last column of Table 2 provides the summary of the calibration results.

\section{Profile Data Collection}

TxDOT's high speed inertia profiler (see Figure 4) was utilized in this study to conduct a statewide survey on the WIM sites' pavement approach roughness. Figure 2 shows a map of the surveyed WIM sites. WIM scales are typically installed across all lanes as well as in both directions. Data collection was performed on both lanes and in both directions where applicable, following ASTM E950 for Class I profiles (10). Data collection was done by the same personnel using the same profiler in order to maximize consistency. Roughness data was collected starting from $305 \mathrm{~m}(1000 \mathrm{ft})$ preceding the WIM scale to $305 \mathrm{~m}(1000 \mathrm{ft})$ past the WIM scale for a total of approximately $610 \mathrm{~m}$ (2000 ft). As an example, Figure 5 presents an illustration of a WIM approach elevation profile obtained from the aforementioned profiler.

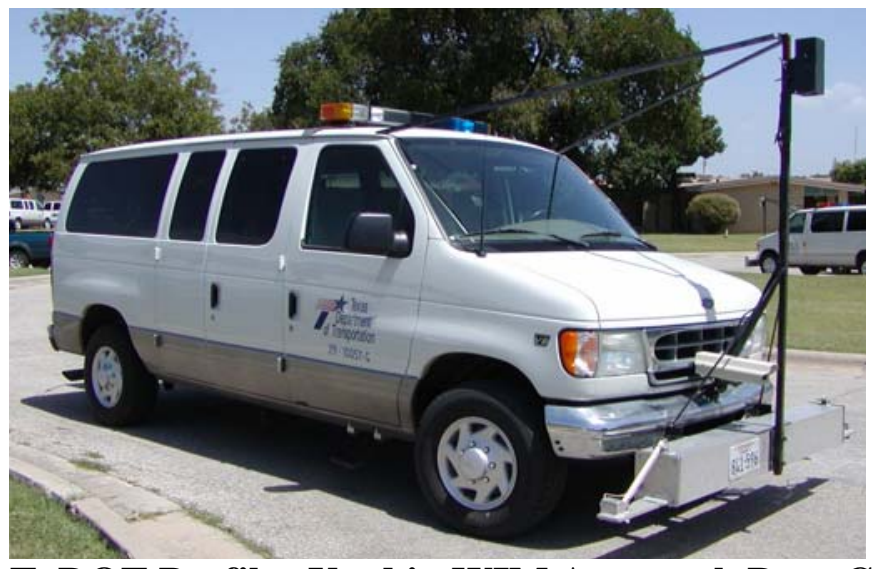

Figure 4. TxDOT Profiler Used in WIM Approach Data Collection. 


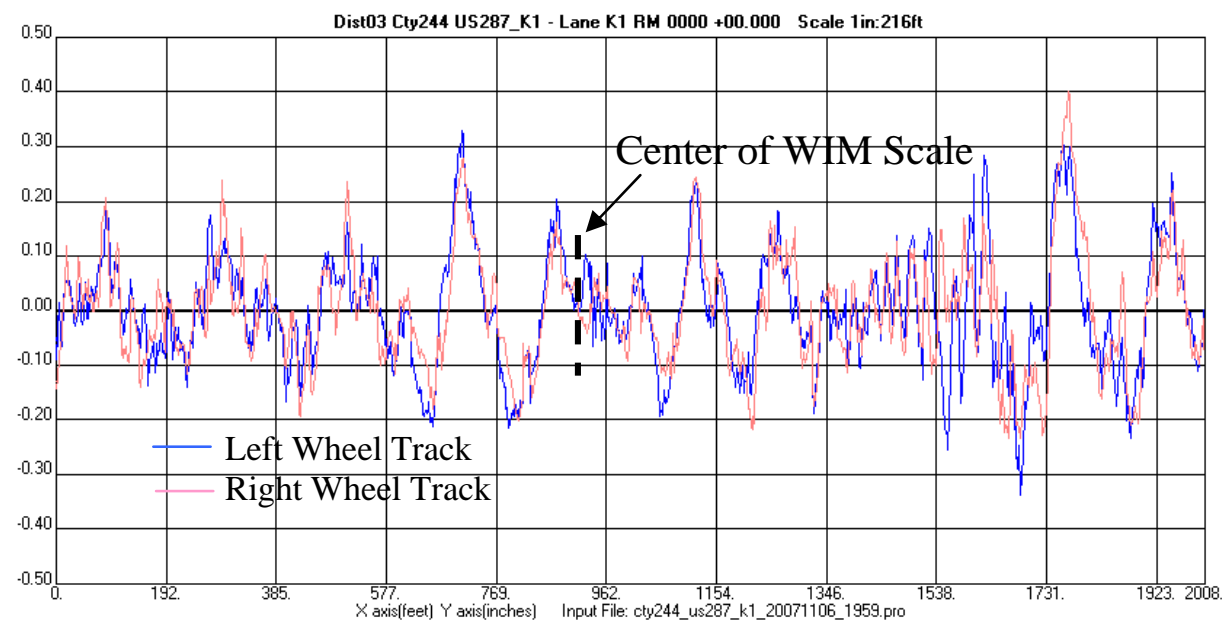

Figure 5. An Example of Pavement Elevations at Both Wheel Tracks From 305 m (1000 ft) Preceding to 305 m (1000 ft) Beyond a WIM Scale.

\section{Data Analyses}

A WIM pavement approach is shown in Figure 6 to facilitate understanding of the roughness index calculation. The software "WIM smoothness index version 1.1" was utilized (with assistance from the Federal Highway Administration) to compute the SRI and LRI indices in this study, as in Figure 7. In addition to calculating SRI or LRI at a given location, the software is able to compute the indices along a distance for each wheel path. As examples, Figures 8 and 9 illustrate two curves representing the change in SRI and LRI along a $610 \mathrm{~m}$ (2000 ft) segment of a smooth and a rough pavement. It is implied that the SRI or LRI at an approach of a given WIM scale corresponds to one point on the SRI or LRI curve. Both SRI and LRI are around the lower threshold in the smooth approach case (Figure 8) while both are around the upper threshold in the rough approach case (Figure 9). LWT and RWT in Figures 8 and 9 denote the left wheel path and right wheel path, respectively.

\section{Driving Direction}

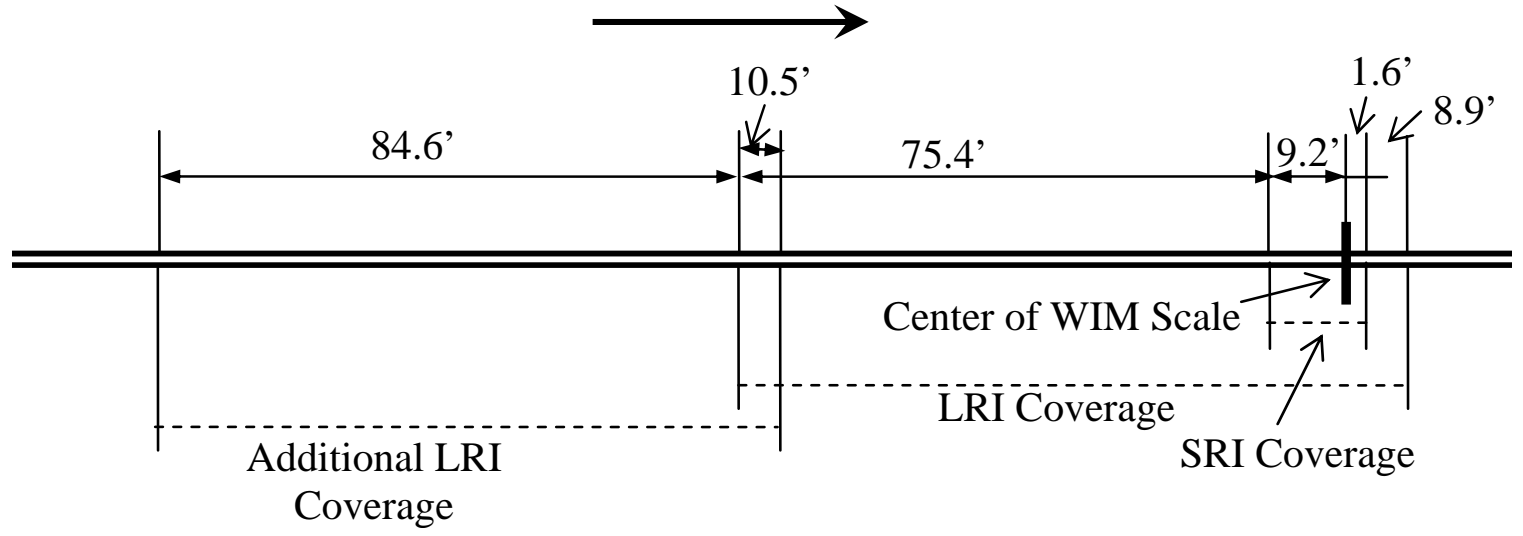

Figure 6. Schematic of Pavement Approach Profile Collection at a WIM Site for Roughness Index Calculation. 


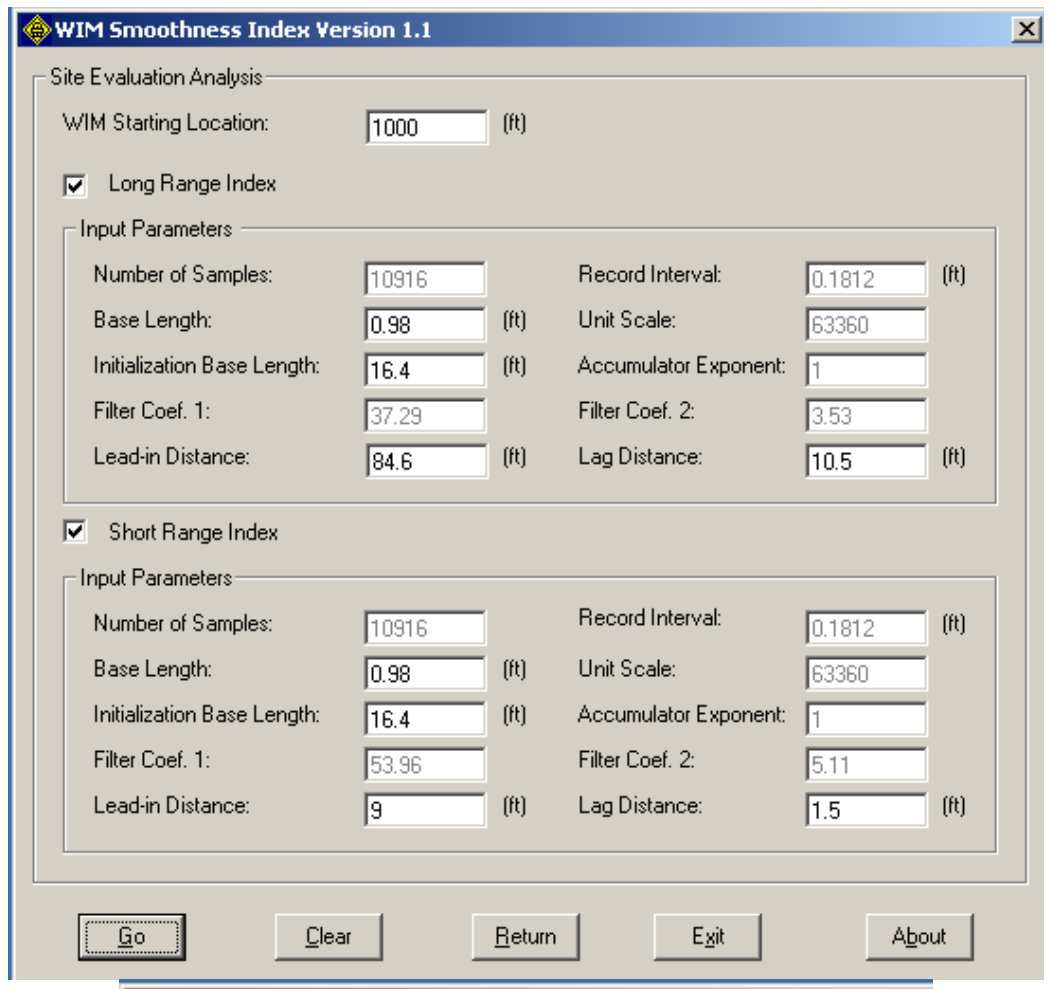

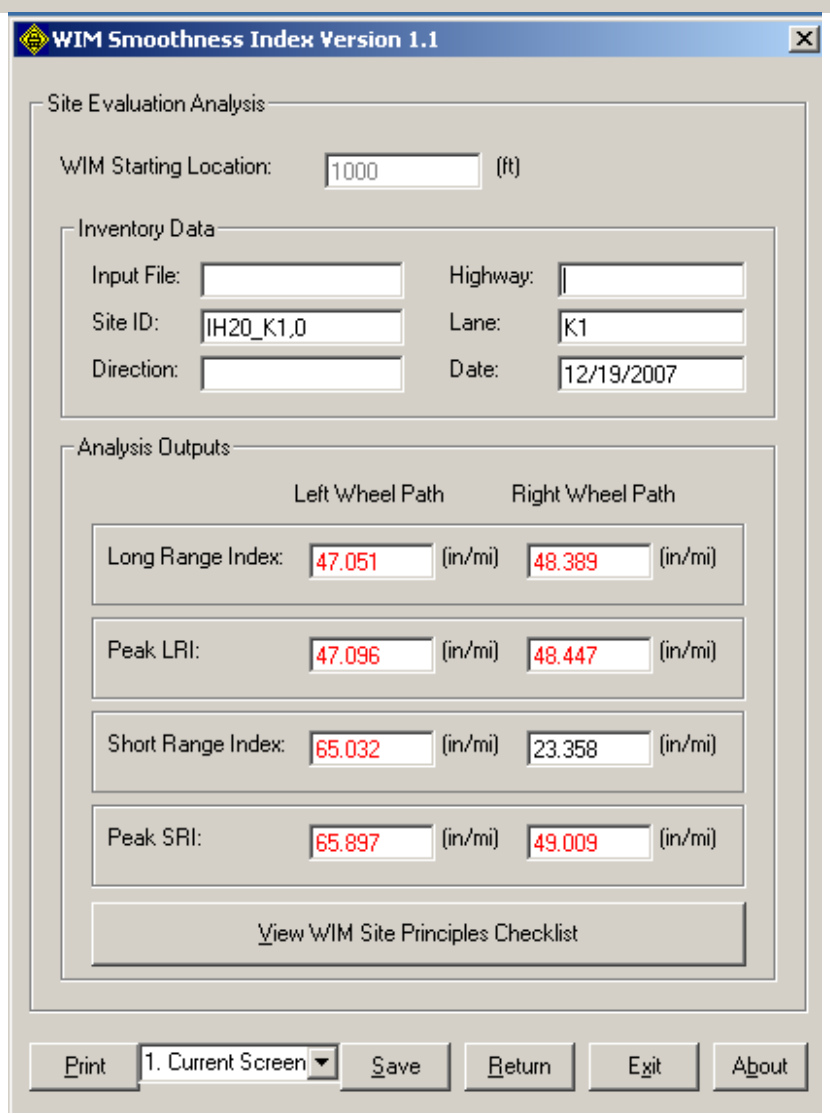

Figure 7. A Snapshot Example of WIM Approach Smoothness Index Calculation Software by LTPP. 

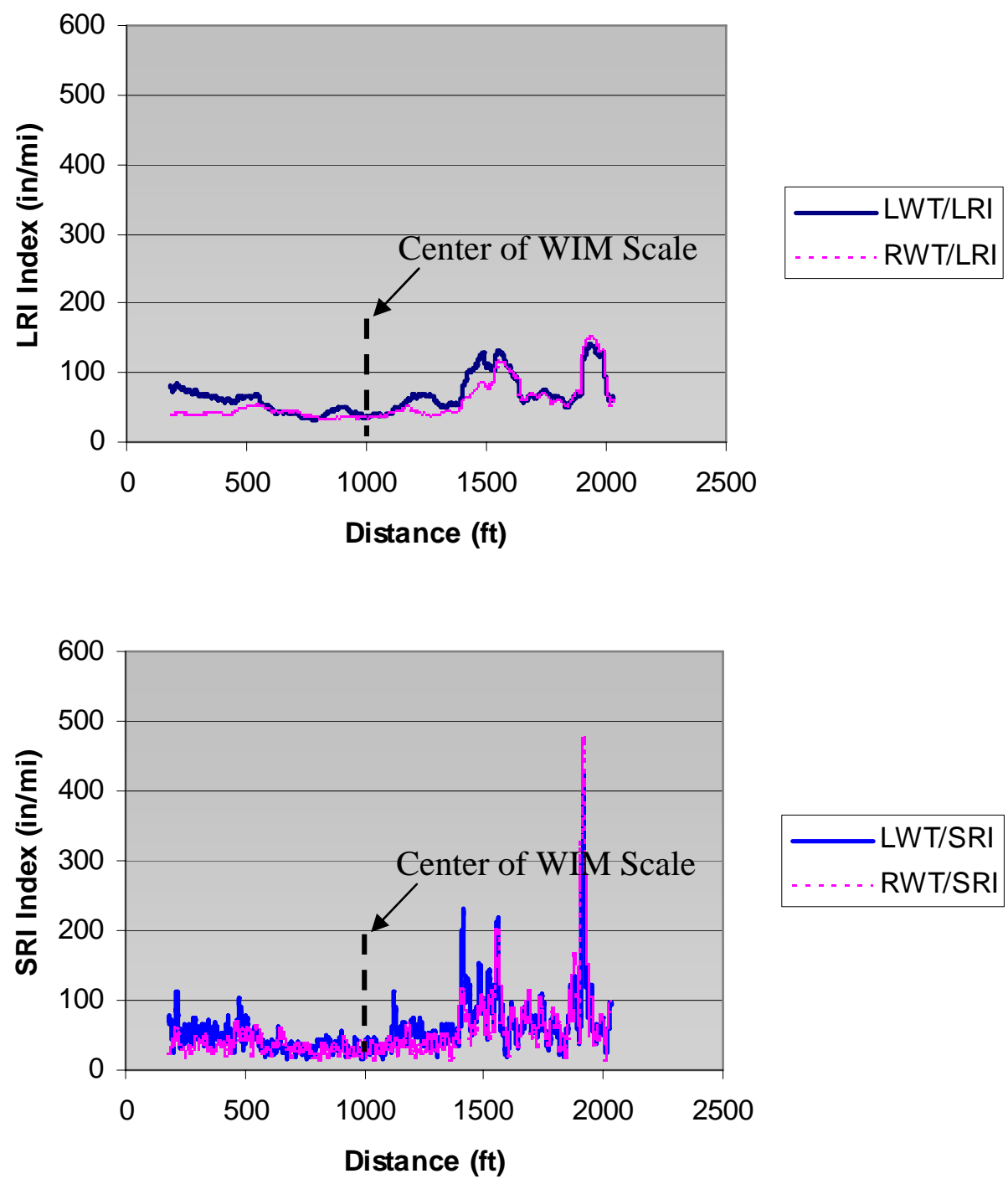

Figure 8. An Example of WIM Site with Smooth Approach (WIM 532 at Lane K6, SH 130). 

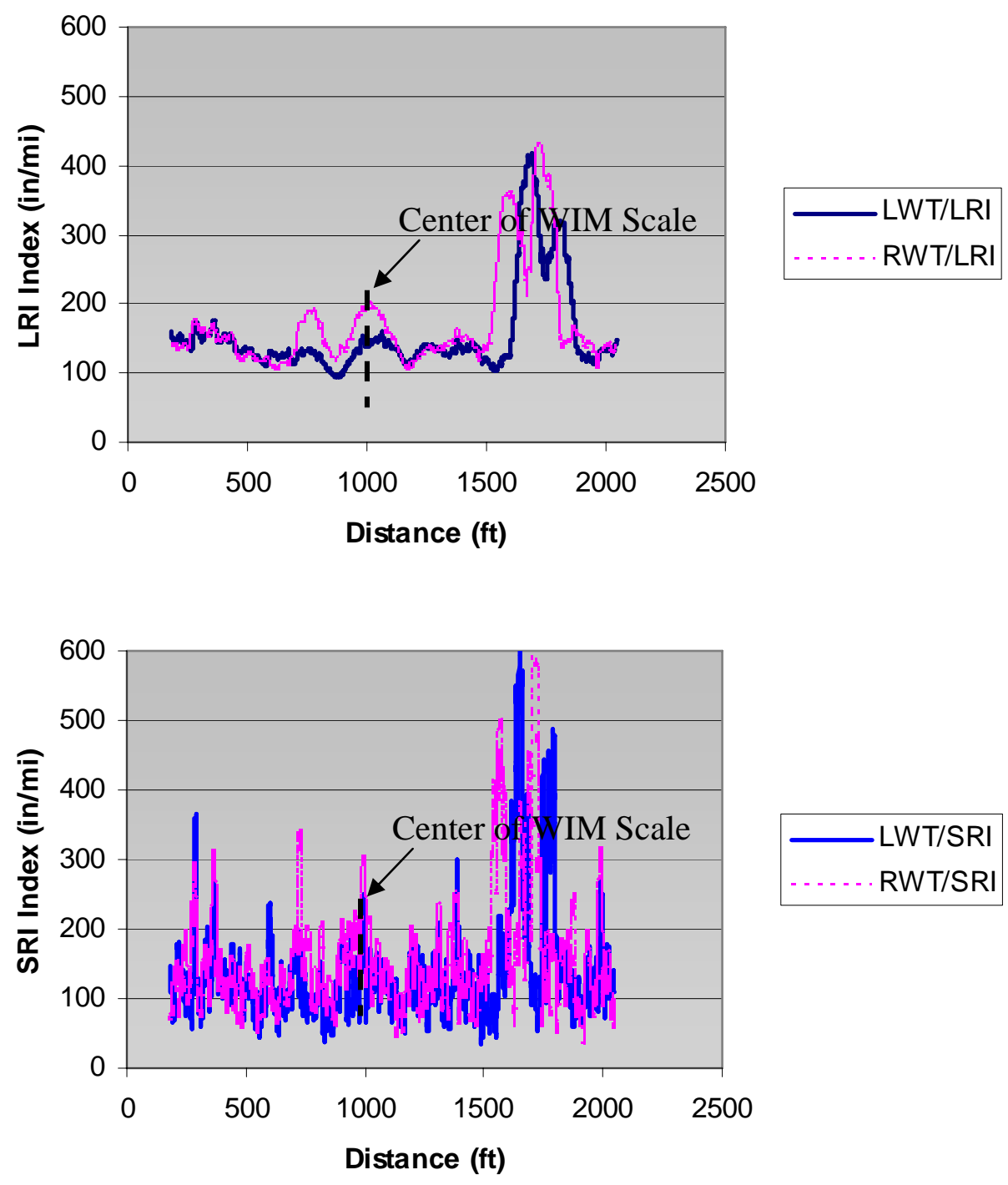

\section{Figure 9. An Example of WIM Site with Rough Approach (WIM 4152 at Lane K1, SH 146).}

Table 2 also incorporates the computed SRI and LRI results from all 70 WIM profiles. For simplicity, only the maximum values from the left and right wheel paths are presented here, along with the WIM calibration records indicating if the weighing error was acceptable. In Table 2 , it is obvious that almost all index values fall within the lower and upper threshold values. Also, the locations that yielded an unacceptable weighing error are strongly correlated to high roughness values.

Figures 10 and 11 present histograms of SRI and LRI, respectively, across all 70 profiles. The summary statistics of these indices are provided in Table 3. For comparison purposes, the lower and upper threshold values suggested by AASHTO MP14 are superimposed on the figures. According to Figure 11, about 95\% of WIM approach lanes have LRI values falling between the 
lower and upper thresholds. Based on the calibration records, the 5\% of WIM lanes exceeding the upper threshold value also yield an unacceptable weighing error. In retrospect, 95\% of WIM sites having LRIs less than the upper threshold value all yielded acceptable weighing error. In Table 2, all lanes that did not yield acceptable weighing error have LRIs equal to or exceeding $2.07 \mathrm{~m} / \mathrm{km}$ (133 in/mi), and they are piezoelectric sensor type WIMs installed in asphalt pavements. WIM 4142 on US 96 has an LRI of $2.07 \mathrm{~m} / \mathrm{km}$ (133 in/mi) (northbound) that yielded unacceptable weighing error. This means the upper threshold value of $2.1 \mathrm{~m} / \mathrm{km}$ needs to be adjusted in order to screen out the locations that yield unacceptable weighing error. The highest LRI value that yielded the acceptable weighing errors is $1.74 \mathrm{~m} / \mathrm{km}(110 \mathrm{in} / \mathrm{mi})$. In other words, when LRIs between $1.74 \mathrm{~m} / \mathrm{km}(110 \mathrm{in} / \mathrm{mi})$ and $2.07 \mathrm{~m} / \mathrm{km}(131 \mathrm{in} / \mathrm{mi})$ represent the range of unknown. Although LRI values less than $2.07 \mathrm{~m} / \mathrm{km}$ (131 in/mi) but higher than 1.74 $\mathrm{m} / \mathrm{km}$ (110 in/mi) may yield acceptable weighing error, it is preferable to use a conservative approach with $1.74 \mathrm{~m} / \mathrm{km}(110 \mathrm{in} / \mathrm{mi})$ as the threshold value.
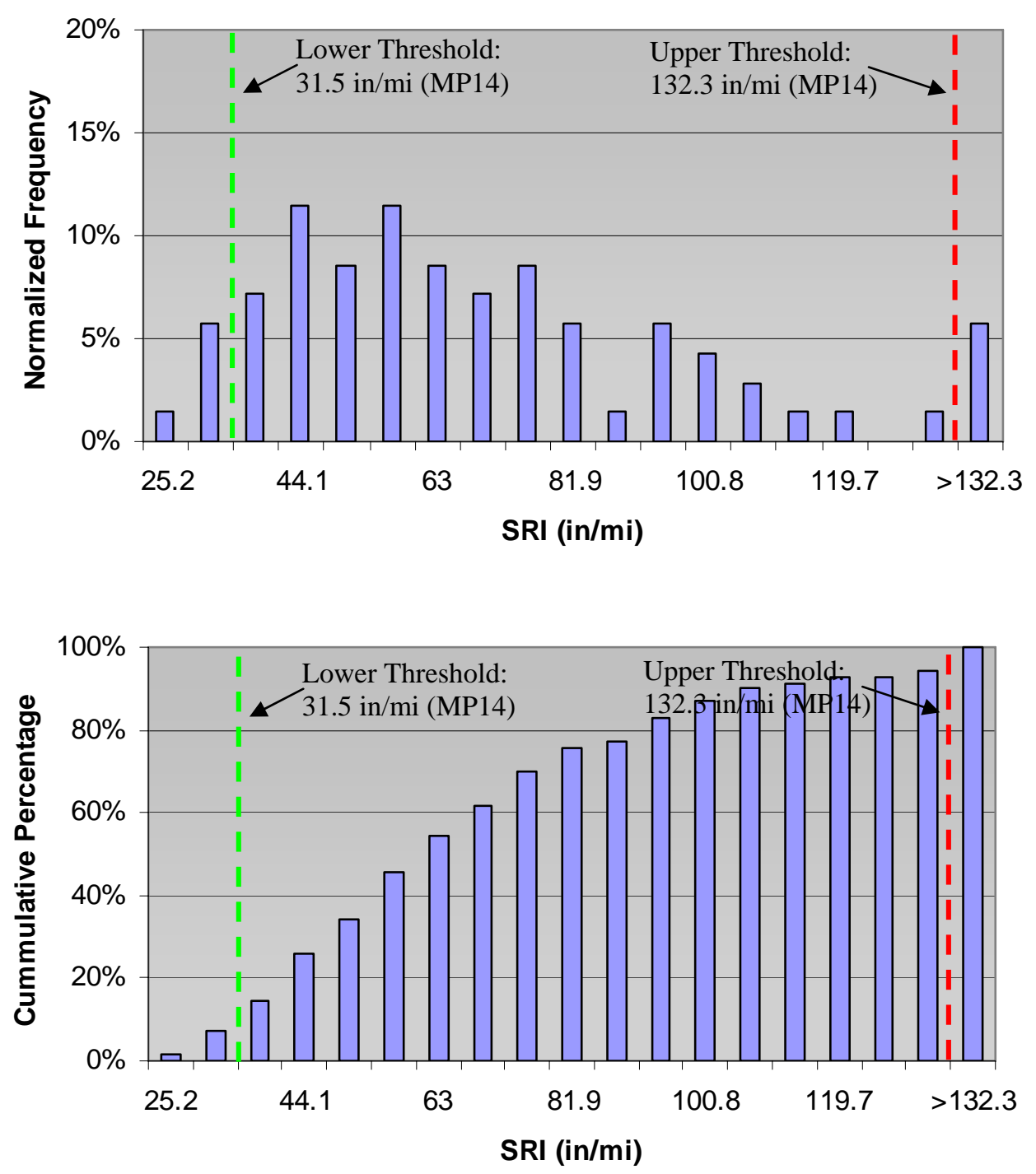

Figure 10. Distribution of Short Range Indices (SRI) for All 70 Pavement Approaches, From $3 \mathrm{~m}$ (10 ft) Preceding the Scale to $0.3 \mathrm{~m}$ (1 ft) Beyond It. 

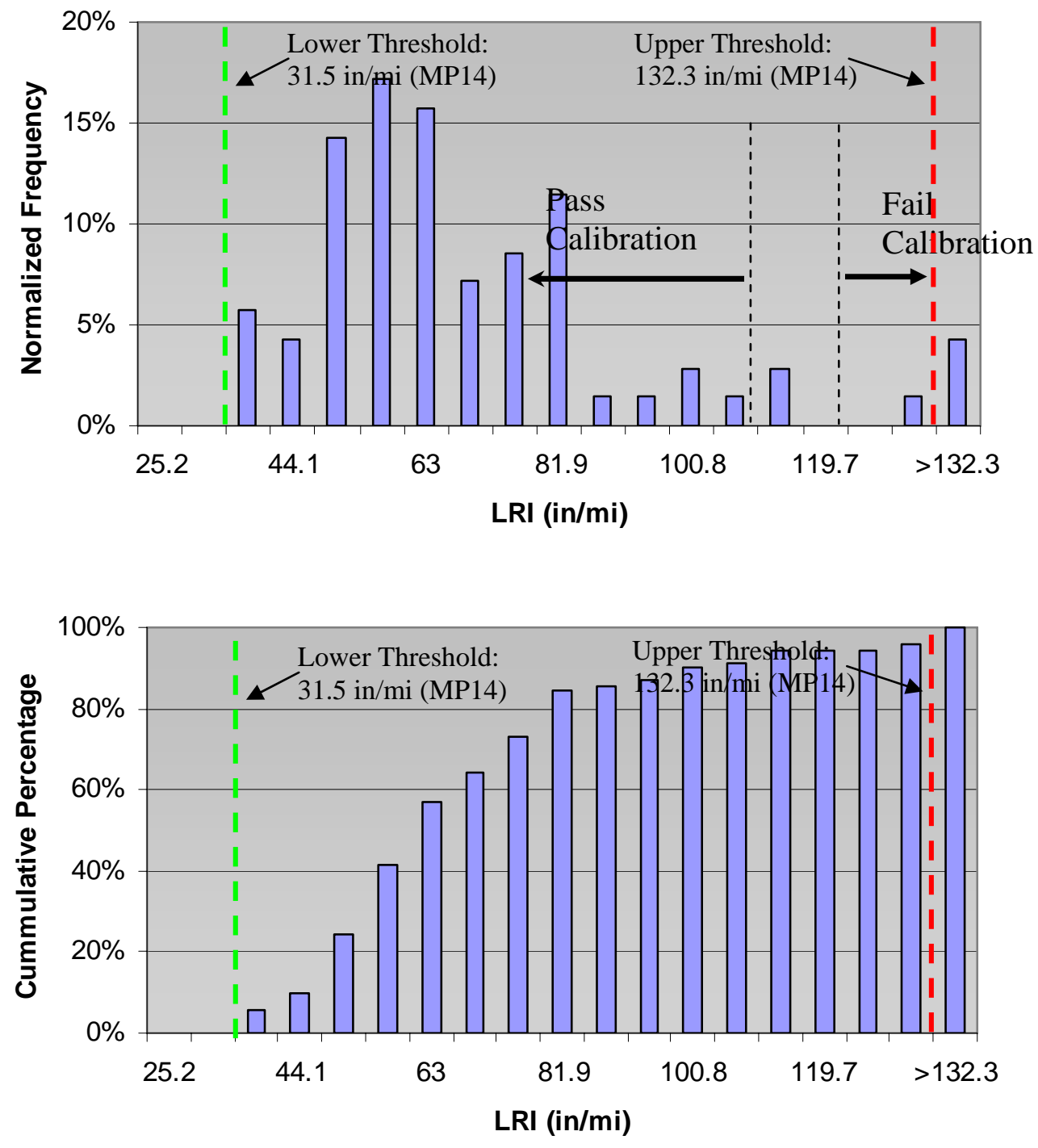

Figure 11. Distribution of Long Range Indices (LRI) for All 70 Pavement Approaches, From $25.8 \mathrm{~m}$ (85 ft) Preceding the Scale to $3.2 \mathrm{~m}$ (11 ft) Beyond It. 
Researchers observed that two lanes that exceeded the upper threshold $(2.1 \mathrm{~m} / \mathrm{km}$ or $133 \mathrm{in} / \mathrm{mi})$ of LRI also exceeded the upper threshold ( $2.1 \mathrm{~m} / \mathrm{km}$ or $133 \mathrm{in} / \mathrm{mi})$ of SRI. However, for two other lanes that exceeded the upper threshold value of SRI the calibration result indicated that the weighing error was acceptable. This indicates that the SRI may be redundant.

In reality, mobilization cost would play a critical role in a short grinding project. This means the

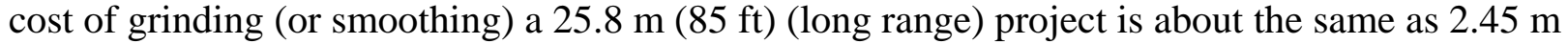
(8 $\mathrm{ft}$ ) (short range) project. In general, the short range smoothness requirement is fulfilled along with the long range requirement. Based on the field measurement and calibration results, an acceptable weighing error will be achieved whenever the LRI threshold value of $1.74 \mathrm{~m} / \mathrm{km}(110$ in/mi) is met, and there is no need to address other requirements (e.g., SRI, peak LRI and peak SRI). The threshold value for peak LRI is the same as for the regular LRI, and there is no need for either kind of SRI.

The $305 \mathrm{~m}(1000 \mathrm{ft})$ of profile data running up to the WIM provides an opportunity to examine the length requirement, as AASHTO MP14 requires $25.8 \mathrm{~m}(85 \mathrm{ft})$ and ASTM E1318 requires 60 $\mathrm{m}(198 \mathrm{ft})$. To determine if the length needs to exceed $25.8 \mathrm{~m}$, an LRI from $25.8 \mathrm{~m}$ (85 ft) to $51.6 \mathrm{~m}$ (170 ft) was computed, assuming the WIM is at $25.8 \mathrm{~m}(85 \mathrm{ft})$, as shown in Figure 6. Figure 12 presents the LRI results from $25.8 \mathrm{~m}(85 \mathrm{ft})$ to $51.6 \mathrm{~m}(170 \mathrm{ft})$, referred to as additional LRI. Its summary statistics are presented in Table 3 . Interestingly, the same sites that yielded the unacceptable weighing error failed again on the additional LRI from $25.8 \mathrm{~m}(85 \mathrm{ft})$ to $51.6 \mathrm{~m}$ $(170 \mathrm{ft})$. There was one approach lane that did not meet the additional LRI upper threshold value of $2.1 \mathrm{~m} / \mathrm{km}$, but yielded acceptable weighing error. Thus, the results indicate that the first 25.8 $\mathrm{m}(85 \mathrm{ft}$ ) preceding the WIM scale is the most critical factor. Furthermore, the results suggest that there is no need to control the roughness outside of the $25.8 \mathrm{~m}(85 \mathrm{ft})$ range. This finding for length requirement is helpful in focusing effort and resources on the $25.8 \mathrm{~m}(85 \mathrm{ft})$ preceding the WIM scale, rather than the $60 \mathrm{~m}(198 \mathrm{ft})$ required by ASTM E1318.

In reality, the preceding slab needs an additional $15 \mathrm{~m}$ (50 ft) for construction space, thus, the minimum preceding slab length is proposed to be $40.8 \mathrm{~m}$ (135 ft) with $25.8 \mathrm{~m}(85 \mathrm{ft})$ with an LRI value equal or less than $1.74 \mathrm{~m} / \mathrm{km}(110 \mathrm{in} / \mathrm{mi})$.

An effort was made to determine the correlation coefficient between SRI and LRI. It was found to be 0.53 , which does not indicate a strong correlation among the 70 profiles investigated in this

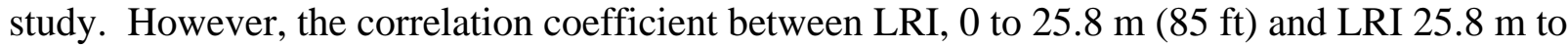

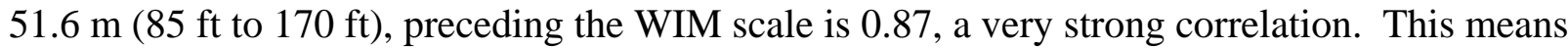
there is a similar degree of roughness in the 0 to $25.8 \mathrm{~m} \mathrm{(} 85 \mathrm{ft}$ ) and $25.8 \mathrm{~m}$ to $51.6 \mathrm{~m}$ ( $85 \mathrm{ft}$ to $170 \mathrm{ft}$ ) ranges preceding the WIM scale. 

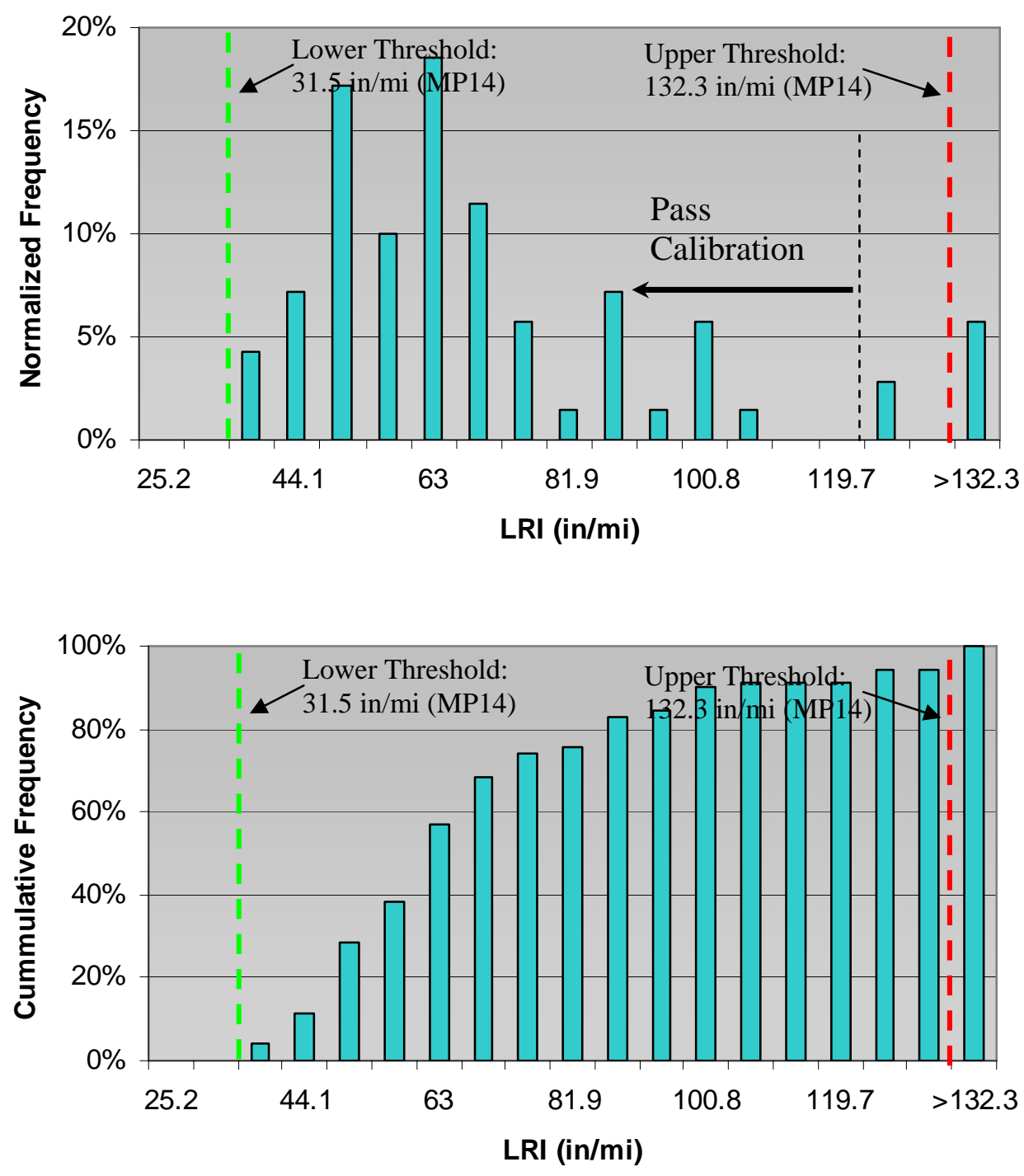

Figure 12. Distribution of Long Range Indices (Additional LRI) at Pavement Approaches, $25.8 \mathrm{~m}$ (85ft) to $51.6 \mathrm{~m}$ (170 ft), Preceding the Scale Across All WIM Sites.

Table 3. Summary Statistics of SRI and LRI Across All WIM Approaches.

\begin{tabular}{|c|c|c|c|c|c|}
\hline Location & Index & Min & Max & Mean & Stdev \\
\hline \multirow{2}{*}{ At Scale† } & $\begin{array}{c}\text { SRI (m/km) } \\
/(\mathrm{in} / \mathrm{mi})\end{array}$ & $\begin{array}{l}0.50 \\
/ 31.5 \\
\end{array}$ & $\begin{array}{c}3.86 \\
/ 243.2 \\
\end{array}$ & $\begin{array}{c}1.09 \\
/ 68.7\end{array}$ & $\begin{array}{l}0.54 \\
/ 34.0\end{array}$ \\
\hline & $\begin{array}{c}\text { LRI(m/km) } \\
\text { /(in/mi) }\end{array}$ & $\begin{array}{l}0.30 \\
/ 18.9 \\
\end{array}$ & $\begin{array}{c}3.48 \\
/ 219.2 \\
\end{array}$ & $\begin{array}{c}1.10 \\
/ 69.3 \\
\end{array}$ & $\begin{array}{c}0.61 \\
/ 38.4 \\
\end{array}$ \\
\hline $\begin{array}{c}\text { Preceding } \\
\text { Scale } \neq\end{array}$ & $\begin{array}{c}\text { LRI(m/km) } \\
/(\mathrm{in} / \mathrm{mi})\end{array}$ & $\begin{array}{c}0.54 \\
/ 34.0 \\
\end{array}$ & $\begin{array}{c}4.29 \\
/ 270.0 \\
\end{array}$ & $\begin{array}{c}1.11 \\
/ 69.9 \\
\end{array}$ & $\begin{array}{l}0.58 \\
/ 36.5 \\
\end{array}$ \\
\hline
\end{tabular}




\section{Conclusions}

Traffic is one of the most critical elements in transportation infrastructure planning and pavement design and is a variable that introduces a high degree of uncertainty. Efforts were made in this study to determine appropriate threshold values and appropriate profile lengths preceding a Weigh-in-Motion (WIM) scale. Roughness data from 19 WIM sites were collected, and the corresponding calibration records from those WIM sites were employed to verify the smoothness threshold values proposed by AASHTO MP14 and ASTM E1318. Since there are multiple lanes at each WIM site, a total of 70 profiles was surveyed. Field data from this study provides opportunities to resolve the requirement discrepancies between AASHTO MP14 and ASTM E1318. Observations and conclusions are given as follows:

1. Based on the calibration records from the WIM sites and field roughness measurements, the upper threshold value of LRI from AASHTO MP14 was able to screen out the locations that yield unacceptable weighing error.

2. More than $90 \%$ of WIM sites yielded acceptable weighing error even when exceeding the lower threshold value. This indicates that the lower threshold value is redundant.

3. The LRI is preferable to the SRI, as it matched better with the WIM calibration results.

4. Based on the 70 profiles investigated for determining appropriate profile lengths, a distance

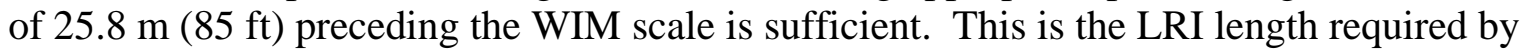
AASHTO MP14. This suggests that the ASTM requirement of $60 \mathrm{~m}$ (198 ft) is too conservative.

5. In order to screen out the locations that yield unacceptable weighing error the upper threshold value of $2.1 \mathrm{~m} / \mathrm{km}(133 \mathrm{in} / \mathrm{mi})$ needs to be adjusted. Although LRI values less than 2.07 $\mathrm{m} / \mathrm{km}$ (131 in/mi) but higher than $1.74 \mathrm{~m} / \mathrm{km}$ (110 in/mi) may yield acceptable weighing error, it is preferable to use a conservative approach with $1.74 \mathrm{~m} / \mathrm{km}(110 \mathrm{in} / \mathrm{mi})$ as the threshold value. Thus, an LRI of $1.74 \mathrm{~m} / \mathrm{km}$ (110 in/mi) for the $25.8 \mathrm{~m}(85 \mathrm{ft})$ preceding the WIM is the only critical factor, and it is the threshold value recommended by this study. However, in reality the preceding slab needs an additional $15 \mathrm{~m}(50 \mathrm{ft})$ for construction space thus, the minimum preceding slab length is $40.8 \mathrm{~m}(135 \mathrm{ft})$ with $25.8(85 \mathrm{ft}) \mathrm{m}$ has LRI value equal or less than $1.74 \mathrm{~m} / \mathrm{km}(110 \mathrm{in} / \mathrm{mi})$. 


\section{References}

1. Prozzi, J. A. and Hong, F. Effect of Weigh-in-Motion System Measurement Errors on LoadPavement Impact Estimation. Journal of Transportation Engineering, ASCE, Vol. 133, No. 1, 2007, pp. 1-10.

2. Hong, F. Prozzi, J. A. and Leung, A. Effect of Traffic Load Measurement Bias on Pavement Life Prediction: A Mechanistic-Empirical Perspective. Journal of Transportation Research Board, 2008.

3. American Association of State Highway and Transportation Officials (AASHTO). Standard Specification for Smoothness of Pavement at the Approaches to Weigh-In-Motion (WIM) Scales. AASHTO Designation: MP14, 2005.

4. Lee, C. E. Factors that Affect the Accuracy of WIM Systems. Precedings, Third National Conference on Weigh-in-Motion, St. Paul, MN, 1998.

5. Karamihas, S. M. and Gillespie, T.D. Smoothness Criteria for WIM Scale Approaches. University of Michigan Transportation Research Institute, Ann Arbor, Michigan, September 2002.

6. Karamihas, S. M. and Gillespie, T.D. Advancing Smoothness Criteria for WIM Scale Approaches - Final Report. University of Michigan Transportation Research Institute, Ann Arbor, Michigan, April 2004.

7. American Society for Testing and Materials (ASTM). Standard Specification for Highway Weigh-in-Motion (WIM) Systems with User Requirements and Test Methods. ASTM Designation: E1318, 2002.

8. Federal Highway Administration, Office of Infrastructure Research, Development, and Technology. Pavement Smoothness Specifications for LTPP WIM Locations, Draft. McLean, Virginia.

9. Wang, F., Hong, F., and Prozzi, J. A. Evaluation of Equipment, Methods, and Pavement Design Implications for Texas Conditions of the AASHTO 2002 Axle Load Spectra Traffic Methodology: Literature Review and Level 1 Data. Research Report No. FHWA/TX-06/04510-2, Center for Transportation Research, The University of Texas at Austin, 2006.

10. American Society for Testing and Materials (ASTM). Standard Test Method for Measuring the Longitudinal Profile of Traveled Surfaces with an Accelerometer Established Inertial Profiling Reference. ASTM Designation: E950, 2004 ”. 